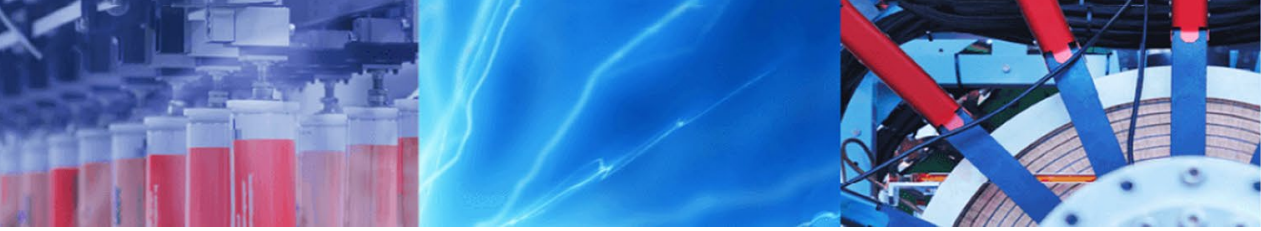

Research Article

\title{
Adsorptive performance of magnetic nano-biosorbent for binary dyes and investigation of comparative biosorption
}

\author{
Tuba Tarhan $^{1,2} \cdot$ Bilsen Tural $^{1}$ (D) $\cdot$ Kenan Boga $^{1} \cdot$ Servet Tural ${ }^{1}$
}

(c) Springer Nature Switzerland AG 2018

\begin{abstract}
The individual and competitive biosorption capacities of Metanil Yellow (MY) and Reactive Black 5 (RB5) by glutaraldehyde cross-linked magnetic chitosan nanoparticles (GMCNs) were studied. Competitive biosorption of the MY and RB5 dyes by the GMCNs has never been reported previously. Fourier transform infrared technique has been used to show the biosorbed MY and RB5 dyes onto GMCNs. During the studies, various essential factors influencing the biosorption, like adsorbate concentration, $\mathrm{pH}$ of the solution and contact time have been monitored. The equilibrium was achieved within $17 \mathrm{~h}$ for single dyes and $3 \mathrm{~h}$ for binary mixture at $\mathrm{pH}$ 3. The biosorption capacities were $620 \mathrm{mg} / \mathrm{g}$ for dye MY and $2549 \mathrm{mg} / \mathrm{g}$ for dye $\mathrm{RB} 5$ at $\mathrm{pH} 3,30^{\circ} \mathrm{C}$. The second-order kinetic model has good compatibility with the dynamical biosorption behavior of a single dye and binary mixture. In order to study the competition biosorption of the RB5 and MY dyes in mixture solutions, the intraparticle diffusion model was used. Competition biosorption through analysis of the intraparticle diffusion model apparently favored the RB5 dye more than the MY dye on the GMCNs in mixture solutions. The biosorbent was regenerated efficiently through the alkaline solution and was then reused ten times for biosorption-desorption cycles.
\end{abstract}

Keywords Magnetic cross-linked chitosan · Biosorption · Azo dyes · Competition · Regeneration

\section{Introduction}

There are many studies in the literature related to the removal of dyes and heavy metals from industrial effluents [14]. The abundance of these kinds of studies results from the significant effects of these two pollutants on environment. In many industrial fields, dyes are widely used in order to colorize products, and by this way, a large quantity of colored wastewater is produced [3,39], generating a substantial volume of colored industrial wastewaters. However, over 100,000 commercially obtainable dyes consist and much more than $7 \times 10^{5}$ tons are manufactured per annum [22].

Unfortunately, industrial dyes, specifically azo dyes which include aromatic structures, are comprised of tenacious dye molecules. Therefore, these dye molecules are proof of aerobic digestion and are steady in oxidizing agents. Furthermore, many industrial dye pollutions are toxic and may be carcinogenic $[8,14]$. Many works have been carried out on the different feasible techniques in order to remove dyes in industrial wastewater. The classical methods for the removal of dye, like biodegradation, oxidation, activated sludge, chemical coagulation, adsorption, photodegradation, electrocoagulation, molecularly imprinted polymers and membrane separation, have been comprehensively investigated $[4,14,21,23]$. On the other hand, cost-efficient biosorbents with high biosorption capabilities have so far been developed to lower the amount of biosorbent dose and reduce the problem of removal. The considerable note has been guided toward a number of biosorbent materials, like biopolymers, bacterial biomass and fungal, which may be acquired in

Bilsen Tural, bilsentural@gmail.com | 'Department of Chemistry, Faculty of Education, Dicle University, 21280 Diyarbakir, Turkey. ${ }^{2}$ Vocational High School of Health Services, Mardin Artuklu University, 47100 Mardin, Turkey.

SN Applied Sciences (2019) 1:8 | https://doi.org/10.1007/s42452-018-0011-1

Received: 2 July 2018 / Accepted: 26 September 2018 / Published online: 4 October 2018 
substantial amounts and are non-hazardous to the environment [14].

Chitosan, the derivative of chitin and natural aminopolysaccharide, is widely used as one of the best polysaccharide adsorbents that remove proteins, dyes, metal ions and other industrial wastes from aqueous solutions. In addition, this polysaccharide derived from chitin has been utilized in industrial wastewater applications $[5,17$, $33,34,36]$. On the other hand, most of the amino groups of chitosan are completely protonated at nearly pH 3.0, and the positively charged chitosan polysaccharide crumbles in the acidic medium. It causes its dissolution in this acidic $\mathrm{pH}$ value. Therefore, the cross-linking reaction methods of chitosan with several cross-linking agents have been investigated in order to enhance its chemical steadiness in any acidic medium during the extraction of dyes from environmental pollution. Chiou et al. investigated the adsorption of various dyes onto the chemical cross-linked chitosan polysaccharide with the cross-linking agent epichlorohydrin [10-13]. Wang et al. [32] prepared the cryogels with acrylamide (AAm) and dimethyl diallyl ammonium chloride (DDAC) as the monomers and used $N, N^{\prime}$-methylene-bis acrylamide (MBA) as the cross-linker for the efficient removal of Reactive Red 141 (RR 141) from an aqueous solution. Rosa et al. [24] used the quaternary chitosan salt cross-linked with the cross-linking agent glutaraldehyde for the adsorption of Reactive Orange 16 dye (AO16). Hu et al. [19] and Du et al. [15] studied on the adsorption of Acid Green 27 (AG27) and Eosin Y dyes, individually, on the chitosan nanoparticles which are synthesized by ionic gelation using sodium tripolyphosphate. On the other hand, Elwakeel [16] synthesized magnetic chitosan beads for the removal of Reactive Black 5 (RB5) dye. Chen et al. $[6,7]$ used the chitosan microparticles with the cross-linking agent glutaraldehyde for the adsorption of RB5 and Remazol Brilliant Orange (3R) dyes and also used chitosan microparticles with the cross-linking agent epichlorohydrin for the biosorption of dyes. Even though the cross-linking reaction technique improves the strength of chitosan polysaccharide against the acidic medium, the procedure decreases its adsorption capability for dyes. It can be considered that the cross-linking method reduces the total amount of hydroxyl and amino groups which are expected to play an important role in the adsorption procedure.

In the recent studies, there has been increased interest greater than before for the use of magnetically supported separation procedure which is another technique for centrifugation or filtration separation procedures depending upon the utilization of magnetic nanoparticles (MNPs) [25, $27,35,38]$.

In the magnetically supported separation technique, functionalized MNPs are distributed into the solution including target molecules, and subsequently, the adsorption of the molecules on the surface of functionalized MNPs takes place, and then, the adsorbed compounds are accumulated quickly and suitably the use of the external magnetic field. The elimination of these MNPs from the aqueous solution with the use of the external magnetic field is more discriminating and effective rather than the other separation techniques (centrifugation or filtration) [29, 35, 38].

The aim of the present study is to examine the GMCNs as biosorbent of the binary dyes, evaluate the best operating conditions of the process, such as dosage, $\mathrm{pH}$, and contact, time and also investigate the kinetic, equilibrium isotherm and desorption. The competitive biosorption behavior of the azo dyes in the admixture solutions was also measured in the cases of lower and higher beginning dye concentrations.

\section{Materials and methods}

\subsection{Chemicals}

The solution of glutaraldehyde $\left(25\right.$ wt $\%$ in $\mathrm{H}_{2} \mathrm{O}$, $\mathrm{C}_{5} \mathrm{H}_{8} \mathrm{O}_{2}$ ), mineral oil, Tween-80, sodium acetate trihydrate $\left(\mathrm{C}_{2} \mathrm{H}_{3} \mathrm{NaO}_{2} \cdot 3 \mathrm{H}_{2} \mathrm{O}\right)$, iron (III) chloride hexahydrate $\left(\mathrm{FeCl}_{3} \cdot 6 \mathrm{H}_{2} \mathrm{O}\right)$, chitosan low molecular weight (poly (D-glucosamine) deacetylated chitin), iron (II) chloride tetrahydrate $\left(\mathrm{FeCl}_{2} \cdot 4 \mathrm{H}_{2} \mathrm{O}\right)$ and acetone $\left(\mathrm{C}_{3} \mathrm{H}_{6} \mathrm{O}\right)$ was obtained from Sigma-Aldrich. Metanil Yellow $\left(\mathrm{C}_{18} \mathrm{H}_{14} \mathrm{~N}_{3} \mathrm{NaO}_{3} \mathrm{~S}\right)$ and Reactive Black 5 Dye content $\geq 50 \%\left(\mathrm{C}_{26} \mathrm{H}_{21} \mathrm{H}_{5} \mathrm{Na}_{4} \mathrm{O}_{19} \mathrm{~S}_{6}\right)$ were obtained from Fluka. The general features of the used dyes are given in Table 1. All chemicals used were of analytical grade and were used as received without any further purification.

\subsection{Preparation and characterization of GMCNs}

The biosorbent was prepared by following a similar method reported by our group previously $[20,26]$. The biosorbent was characterized in our previous work using scanning electron microscopy (SEM), transmission electron microscopy (TEM), vibrating sample magnetometer (VSM) and Fourier transform infrared spectroscopy (FTIR). Finally, the obtained GMCNs were re-suspended in degassed deionized water and the concentration of the generated GMCNs in suspension was about $10 \mathrm{mg} / \mathrm{mL}$.

\subsection{Biosorption of azo dyes}

Biosorption studies were conducted by using $2.5 \mathrm{~mL}$ of the GMCNs $(10 \mathrm{mg} / \mathrm{mL})$ separated from water solution with a magnet. The batch experiments were carried out 
Table 1 Structures of Reactive Black 5 (RB5) and Metanil Yellow (MY)

\begin{tabular}{|c|c|c|}
\hline Characteristics & RB5 & MY \\
\hline $\begin{array}{l}\text { Structure } \\
{ }^{+} \mathrm{Na}^{-} \mathrm{O}_{3} \mathrm{SOH}_{2} \mathrm{CH}_{2} \mathrm{CO}_{2} \mathrm{~S}\end{array}$ & ${ }_{3}^{-\mathrm{Na}^{+}}$ & \\
\hline $\begin{array}{l}\text { C.I.Number } \\
\text { Formula } \\
\text { Molecular weight }(\mathrm{g} / \mathrm{mol}) \\
\lambda_{\max }(\mathrm{nm})\end{array}$ & $\begin{array}{l}20505 \\
\mathrm{C}_{26} \mathrm{H}_{21} \mathrm{~N}_{5} \mathrm{Na}_{4} \mathrm{O}_{19} \mathrm{~S}_{6} \\
991.82 \\
596\end{array}$ & $\begin{array}{l}13065 \\
\mathrm{C}_{18} \mathrm{H}_{14} \mathrm{~N}_{3} \mathrm{NaO}_{3} \mathrm{~S} \\
375.38 \\
434\end{array}$ \\
\hline
\end{tabular}

in $75-\mathrm{mL}$ glass vials with $2.5 \mathrm{~mL}$ of the GMCNs $(10 \mathrm{mg} /$ $\mathrm{mL}$ ) and $50 \mathrm{~mL}$ of adsorbate solution (MY and RB5). The batch experiments were conducted at room temperature for $24 \mathrm{~h}$. The concentration of MY and RB5 solutions was in the range of $0.15-4.80 \mathrm{mM}$. In order to examine the effect of solution $\mathrm{pH}$, the biosorption experiments were conducted at the concentrations of $0.15 \mathrm{mM}$ for both pollutants. Twenty-five milligrams of biosorbent and $50 \mathrm{~mL}$ of $0.15 \mathrm{mM}$ adsorbate solution were used for the $\mathrm{pH}$-dependent study. $1 \mathrm{M} \mathrm{HCl}$ and $1 \mathrm{M} \mathrm{NaOH}$ were used to adjust the $\mathrm{pH}$ of the MY and RB5 solution. On the other hand, $25 \mathrm{mg}$ of biosorbent and $50 \mathrm{~mL}$ of 1.33 and $0.66 \mathrm{mM}$ adsorbate (MY and RB5) solutions were used for the kinetic studies. At first, the solution mixtures were put into a stirring plate for $24 \mathrm{~h}$. After the biosorption experiments, the samples were collected from GMCNs by $\mathrm{Nd}-\mathrm{Fe}-\mathrm{B}$ permanent magnet. Then, the collected samples were analyzed by a UV-visible spectrophotometer (UV-visible spectrometer Perkin-Elmer Lambda 25). The biosorption maxima were considered at 434 and $597 \mathrm{~nm}$ for MY and RB5, respectively. The $\mathrm{pH}$ was adjusted to 6 using either hydrochloric acid or sodium hydroxide standardized solutions because the $\lambda$ max of dye solution can be varied at different pHs $[11,28]$. The biosorption capacity $(\mathrm{Q})$ was calculated by using the following equations.

$Q=\frac{\left(C_{\mathrm{i}}-C_{\mathrm{f}}\right) V}{W}$

where $V$ is the sample volume $(\mathrm{mL}) ; C_{i}$ is the initial concentration of dye $(\mathrm{mg} / \mathrm{mL}) ; C_{\mathrm{f}}$ is the equilibrium concentration of the MY and RB5 solutions ( $\mathrm{mg} \mathrm{L}^{-1}$ ); $Q$ is the biosorption capacity $(\mathrm{mg} / \mathrm{g}$ ) of GMCNs; and W is the weight of the biosorbent (mg). The dyes adsorbed GMCNs were characterized using Fourier transformed infrared (FTIR, Thermo Scientific Nicolet IS10 FTIR spectrometer).

The process of dye biosorption by GMCNs as a function of time was estimated by kinetic models of pseudofirst order and pseudo-second order. These models are expressed by the following equations.

Pseudo-first-order Eq. (2) is as follows:

$\ln \left(Q_{e}-Q_{t}\right)=\ln \left(Q_{e}\right)-k_{1} t$

Pseudo-second-order Eq. (3) is as follows:

$\frac{t}{Q_{t}}=\frac{1}{\left(k_{2} Q_{e}^{2}\right)}+\frac{t}{Q_{e}}$

where $k_{1}$ is the kinetic constant of pseudo-first-order biosorption $\left(\mathrm{min}^{-1}\right.$ ) and $Q_{t}$ and $Q_{e}$ represent the amounts of adsorbed MY and RB5 onto GMCNs at equilibrium and at time $t$, respectively. A plot of $\ln \left(Q_{e}-Q_{t}\right)$ versus $t$ should provide a straight line, if the pseudo-first-order kinetic model applies for the studied sorption processes. $k_{2}$ is the pseudo-second-order kinetic rate constant $(\mathrm{g} /(\mathrm{mg} \mathrm{min})$ ). According to Eq. (3), a plot of $t / Q_{t}$ versus $t$ gives $k_{2}$ and $Q_{e}$ values from the slope and intercept [8].

The biosorption equilibrium data were evaluated by the isotherms of Langmuir (Eq. (4)) and Freundlich (Eq. (5)) whose equations are given below:

$\frac{1}{q_{e}}=\frac{1}{q_{m} b C_{e}}+\frac{1}{q_{m}}$

$\ln \left(Q_{e}\right)=b_{F} \ln \left(C_{e}\right)+\ln K_{F}$

where $\mathrm{q}_{\mathrm{e}}(\mathrm{mg} / \mathrm{g})$ is the adsorbed amount, $\mathrm{q}_{\mathrm{m}}(\mathrm{mg} / \mathrm{g})$ is the maximum dyes biosorption capability, $K_{F}$ is dye biosorption capability, $C_{e}(\mathrm{mg} / \mathrm{L})$ is the equilibrium concentration 
in solution and $b$ and $b_{F}$ are the Langmuir and Freundlich constants related to biosorption capability and energy of biosorption, respectively.

\subsection{Desorption}

For the desorption study, the dyes were adsorbed on GMCNs material under the optimized biosorption conditions ( $\mathrm{pH}=3 ; \mathrm{C}_{0}=0.67 \mathrm{mM} ; T=30^{\circ} \mathrm{C} ; t=17 \mathrm{~h}$ ). The GMCNs material with biosorbed corresponding dye was used for the desorption study. Deionized water ( $\mathrm{pH}$ between 2 and 12 ranges) was used as eluent for regeneration of the GMCNs biosorbent. After the biosorption stage, by using an $\mathrm{Nd}-\mathrm{Fe}-\mathrm{B}$ permanent magnet, the biosorbent materials were separated from supernatant. The separated biosorbent particles were taken in flasks after being washed with deionized water. To determine the reusability of the GMCNs material, ten successive adsorption-desorption cycles were performed. The concentrations of the desorbed dyes in the supernatants were determined by measuring the absorbance of the solutions at maximum wavelength with a UV-Vis spectrophotometer at room temperature.

\subsection{Competitive study}

It is assumed that the total absorbance of an admixture dye solution is equal to the sum of the absorbance of each dye represented by Eq. (6). There is no interaction between the MY and RB5 dyes. In a binary system with components MY and RB5, dye concentrations were calculated by using Eqs. (7) and (8). After using Eqs. (7) and (8), the capacity of biosorption of MY and RB5 in the mixture solution can be obtained [8].

$A_{\lambda}=A_{\mathrm{RB} 5}+A_{\mathrm{MY}}$

$A_{\lambda}=\varepsilon_{1 \mathrm{RB} 5} L C_{\mathrm{RB} 5}+\varepsilon_{1 \mathrm{MY}} L C_{\mathrm{MY}}$

$A_{\lambda}=\varepsilon_{2 \mathrm{RB} 5} L C_{\mathrm{RB} 5}+\varepsilon_{2 \mathrm{MY}} L C_{\mathrm{MY}}$

where $A_{\lambda}, A_{\lambda 1}$ and $A_{\lambda 2}$ are the absorbance of UV-visible spectrometer at wavelength $\lambda, \lambda_{1}$ and $\lambda_{2}$, respectively; $A_{R B 5}$ and $A_{\mathrm{MY}}$ are the absorbance of RB5 and MY at wavelength $\lambda$, respectively; $\varepsilon_{1 \mathrm{RB} 5}$ and $\varepsilon_{2 \mathrm{RB} 5}$ are the molar absorptivities of pure RB5 at wavelength $\lambda_{1}$ and $\lambda_{2}$, respectively; $\varepsilon_{1 \mathrm{MY}}$ and $\varepsilon_{2 M Y}$ are the absorbance coefficients of pure MY at wavelength $\lambda_{1}$ and $\lambda_{2}$, respectively; $C_{\mathrm{RB} 5}$ and $C_{\mathrm{MY}}$ are the concentrations of MY and RB5 in the mixture solution, respectively; $L$ is the cell with $(1 \mathrm{~cm})$; and $\lambda_{1}(596 \mathrm{~nm})$ and $\lambda_{2}(434 \mathrm{~nm})$ are the wavelengths of maximum absorbance for MY and RB5, respectively, in Fig. 1.

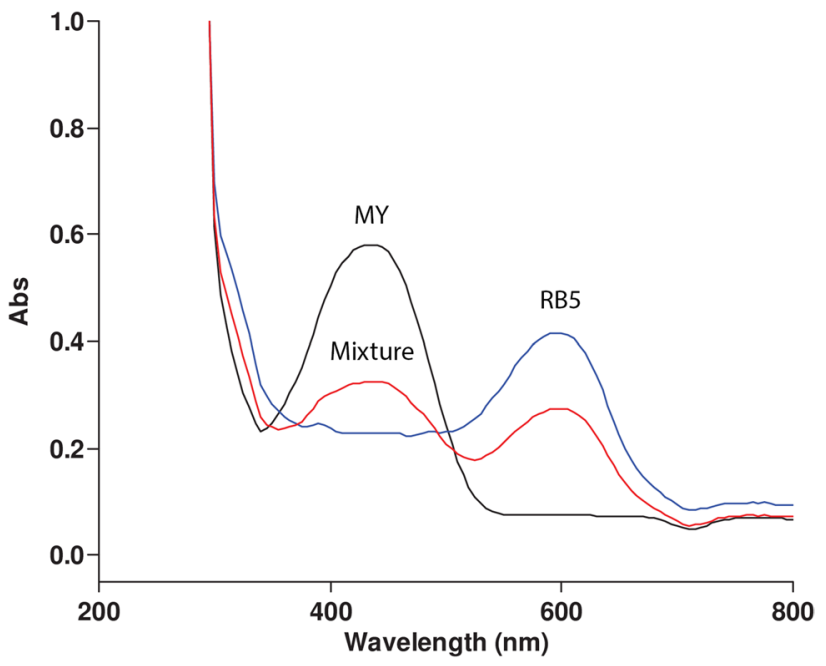

Fig. 1 UV-visible spectra of the RB5, MY and admixture dyes

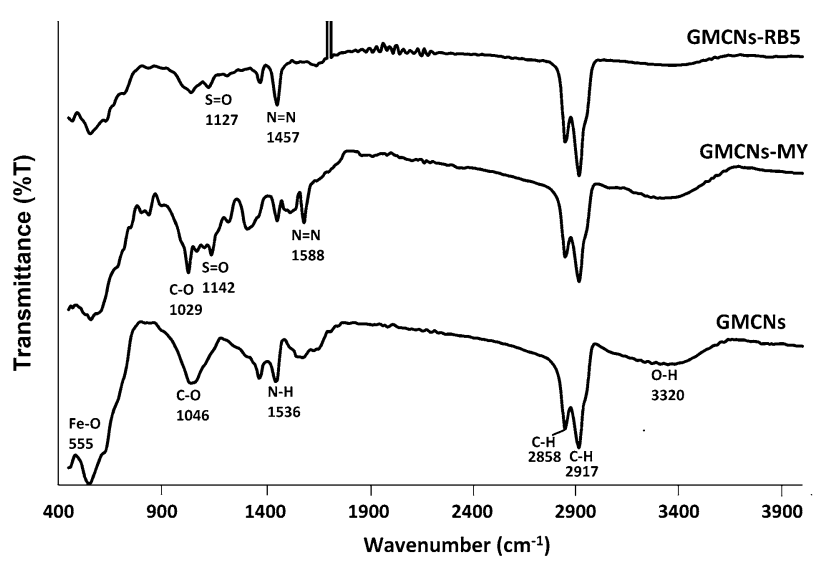

Fig. 2 FTIR spectra of the GMCNs and the GMCNs after the RB5 and MY biosorption

\section{Results and discussion}

\subsection{Characterization of biosorbent}

To ascertain the biosorption of MY dye and RB5 dye on GMCNs, the FTIR spectra of bare GMCNs and dyes (MY and RB5) loaded GMCNs were compared. The spectra for the GMCNs, MY loaded and RB5 loaded GMCNs are illustrated in Fig. 2. The spectrum for GMCNs included $\mathrm{O}-\mathrm{H}$ stretching vibration peak at $3320 \mathrm{~cm}^{-1}$ and $\mathrm{C}-\mathrm{H}$ stretching vibration of the polymer backbone at $2917 \mathrm{~cm}^{-1}$ and $2858 \mathrm{~cm}^{-1}$. The characteristic sorption peak of primary amine $\left(-\mathrm{NH}_{2}\right)$ appears at $1536 \mathrm{~cm}^{-1}$. The sorption band around $1046 \mathrm{~cm}^{-1}$ displays the stretching vibration of $\mathrm{C}-\mathrm{O}$ bond. The biosorption of MY dye and RB5 dye onto GMCNs was confirmed by the presence of characteristic peaks of $\mathrm{S}=\mathrm{O}$ and $\mathrm{N}=\mathrm{N}$ groups (see Fig. 2) $[1,2,37]$. We 
can conclude that MY and RB5 molecules were adsorbed onto the GMCNs by observing these peaks in the FTIR spectrum of GMCNs.

\subsection{Biosorption kinetics}

The biosorption of MY and RB5 onto GMCNs as a function of time is given in Fig. 3. The biosorption process was fast during the first $8 \mathrm{~h}$ for both MY and RB5, and then, the rate was slower during the $8-17 \mathrm{~h}$ range, and a plateau was reached after $17 \mathrm{~h}$. This is due to the existence of high available active sites on the biosorbent surface. It can be seen from this figure that the maximum uptake of MY and RB5 by GMCNs was reached in approximately $17 \mathrm{~h}$ indicating the high affinity of MY and RB5 onto the biosorbent $[8,11,14,16,18,30,31]$. As can be seen from Fig. 3 , reaching the equilibrium state is not significantly related to the initial MY and RB5 concentration. According to Fig. 3, as the initial concentrations of the RB5 and MY dyes increased from 0.67 to $1.3 \mathrm{mM}$, the biosorption capacities of the RB5 and MY dyes on the GMCNs increased from 1.2 to $2.51 \mathrm{mmol} / \mathrm{g}$ and from 0.58 to $1.25 \mathrm{mmol} / \mathrm{g}$, respectively. Under the same biosorption conditions, the maximum biosorption capacity for MY and RB5 was identified to be 1875 and $2389 \mathrm{mg} / \mathrm{g}$, respectively.

Kinetic studies are very important as they provide valuable information about the reaction pathways and also explain the solute uptake rate which in turn controls the residence time of adsorbate at the solid-liquid interface [8, $11,14,16,30,31]$. In order to examine the sorption kinetics of RB5 and MY, correlations between time and biosorbed amounts were looked for, through the analysis of different kinetic models such as pseudo-first order and pseudo-second order. The obtained kinetic parameters and correlation coefficients from pseudo-first-order and pseudo-second-order kinetic models for RB5 and MY biosorption are represented in Table 2. Taking into account, both the equilibrium biosorption $q_{e}$ and the determination coefficient $R^{2}$ in Table 2, the second-order kinetic model fits better than the first-order kinetic model for the RB5 and MY dyes [11].
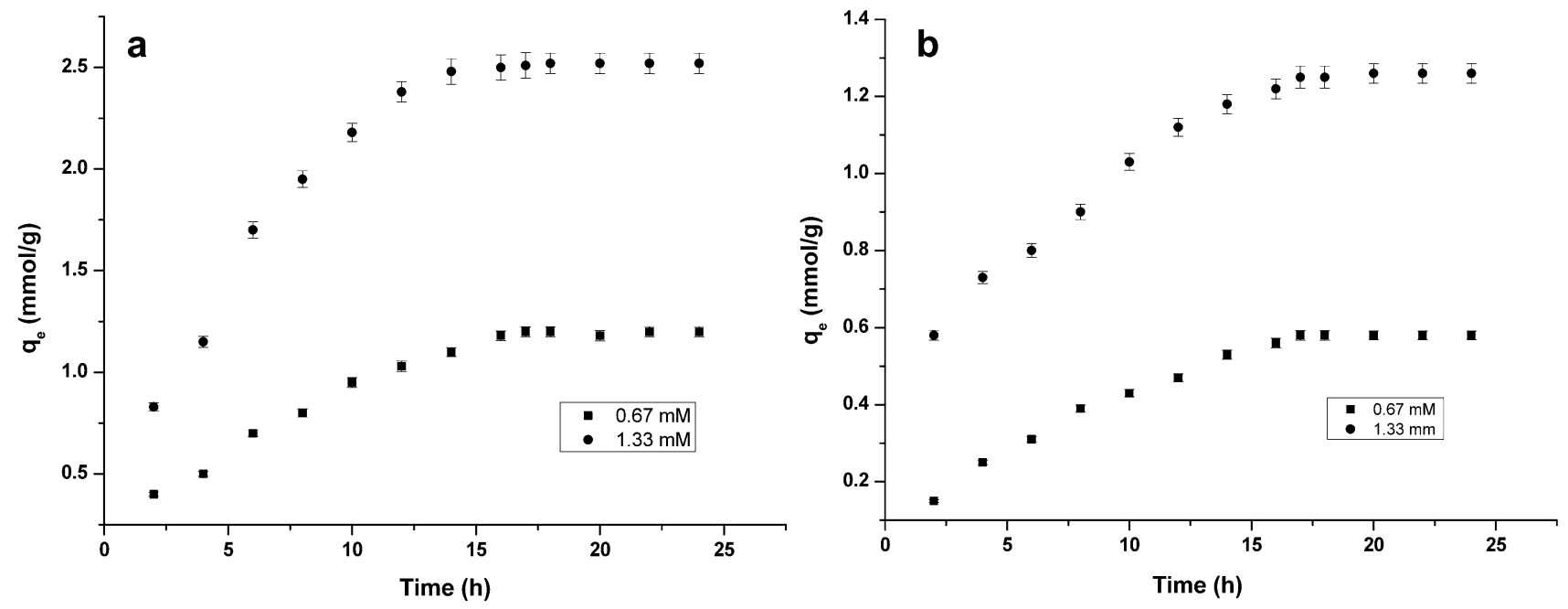

Fig. 3 Effect of time on the biosorption of $\mathbf{a}$ RB5 and $\mathbf{b}$ MY on the GMCNs at pH 3

Table 2 Pseudo-first-order and pseudo-second-order biosorption rate constants, calculated $q_{(e, \text { cal })}$ and experimental $q_{(\mathrm{e}, \mathrm{exp})}$ values for different beginning dye concentrations, at $\mathrm{pH} 3$ and at $30{ }^{\circ} \mathrm{C}$ temperature for the RB5 and $\mathrm{MY}$ dyes on the GMCNs

\begin{tabular}{|c|c|c|c|c|c|c|c|}
\hline & \multicolumn{4}{|c|}{ Pseudo-first-order } & \multicolumn{3}{|c|}{ Pseudo-second-order } \\
\hline & $\begin{array}{l}q_{(\mathrm{e}, \mathrm{exp})} \\
\left(\mathrm{mg} \mathrm{g}^{-1}\right)\end{array}$ & $\begin{array}{l}k_{1} \\
\left(\min ^{-1}\right)\end{array}$ & $\begin{array}{l}q_{(\mathrm{e}, \mathrm{cal})} \\
\left(\mathrm{mg} \mathrm{g}^{-1}\right)\end{array}$ & $R^{2}$ & $\begin{array}{l}k_{2} \\
\left(\mathrm{~g} \mathrm{mg}^{-1} \min ^{-1}\right)\end{array}$ & $q_{(\mathrm{e}, \mathrm{cal})}$ & $\begin{array}{l}R^{2} \\
\left(\mathrm{mg} \mathrm{g}^{-1}\right)\end{array}$ \\
\hline \multicolumn{8}{|c|}{ RB5 (mM) } \\
\hline 0.665 & 1190 & 0.234 & 1914 & 0.877 & $7.83 \mathrm{E}-05$ & 1666 & 0.979 \\
\hline 1.33 & 2490 & 0.363 & 6385 & 0.926 & $5.29 \mathrm{E}-05$ & 3333 & 0.983 \\
\hline \multicolumn{8}{|c|}{$\mathrm{MY}(\mathrm{mM})$} \\
\hline 0.665 & 220 & 0.20 & 313 & 0.918 & $3.28 \mathrm{E}-04$ & 322 & 0.982 \\
\hline 1.33 & 475 & 0.214 & 531 & 0.935 & $3.75 \mathrm{E}-04$ & 588 & 0.991 \\
\hline
\end{tabular}




\subsection{Biosorption equilibrium}

Adsorption isotherms explain how the adsorbate molecules interact with the biosorbent particles and are therefore significant in optimizing the use of chemically treated solid materials. It is possible to illustrate the equilibrium biosorption isotherms by plotting the concentration of the adsorbate in the solid phase against that is in the liquid phase. Figure 4 points out the biosorption isotherms of each dye at $\mathrm{pH} 3,30^{\circ} \mathrm{C}$ and $17 \mathrm{~h}$ using the GMCNs. In the beginning, the equilibrium biosorption capacity, $q_{e}$ increased as concentration of MY and RB5 dyes increased. On the other hand, there was no increase in biosorption capacity of dyes beyond $1 \mathrm{mM}$ concentration (see Fig. 4). In Fig. 4, it is seen that the $q_{e}$ of MY is much smaller than the $q_{e}$ of RB5. In the current study, experimental data were fitted by applying two well-known and widely used isotherm models, namely Langmuir, Freundlich, to obtain the determination coefficients $\left(R^{2}\right)$ and the model parameters which are shown in Table 3. Compared with the linear correlation coefficients, $R^{2}$, the Langmuir biosorption model gave a good fit of the experimental data of the

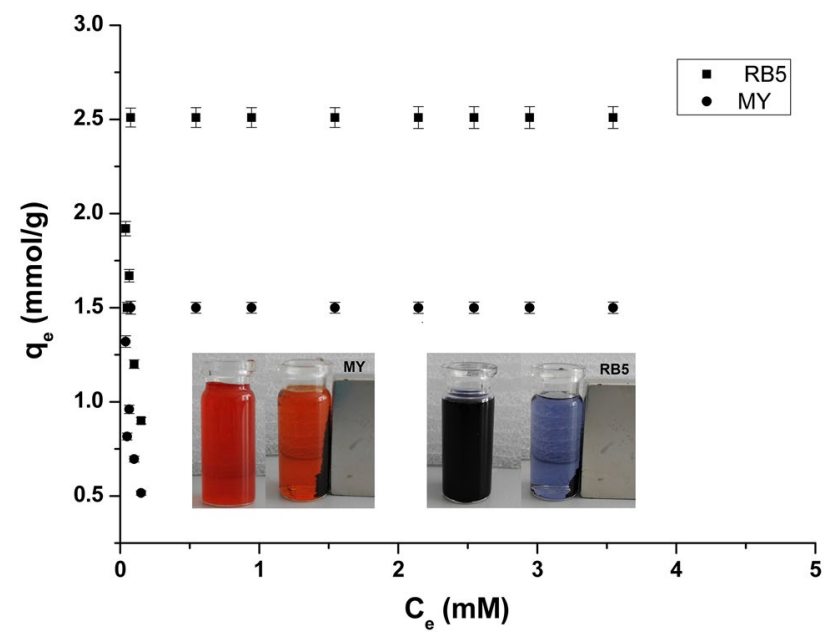

Fig. 4 Effect of preliminary dye concentration on biosorption of the RB5 and MY onto the GMCNs (pH 3; $25 \mathrm{mg} / 50 \mathrm{~mL}$ biosorbent; $30^{\circ} \mathrm{C}$; $200 \mathrm{rpm} ; 17 \mathrm{~h}$ ) and insert of the images before and after biosorption for the RB5 and MY dyes on the GMCNs at $0.67 \mathrm{mM}$
MY dye and the RB5 dye on the GMCNs. Table 3 shows that the computed maximum capacity $\mathrm{Q}_{\mathrm{m}}$ has a large value of $2.57 \mathrm{mmol} \mathrm{g}^{-1}\left(2549 \mathrm{mg} \mathrm{g}^{-1}\right)$ for the RB5 dye and $1.65 \mathrm{mmol} \mathrm{g}^{-1}\left(620 \mathrm{mg} \mathrm{g}^{-1}\right)$ for the MY dye on the GMCNs.

In this research, the elimination efficiencies of RB5 and $\mathrm{MY}$ were examined for the $\mathrm{pH}$ values in the changing range from 3.0 to 10.0 and the results are indicated in Fig. 5. When the $\mathrm{pH}$ of the solution dropped from 10.0 to 3.0, the biosorption capabilities of the RB5 and MY dyes on the GMCNs increased from 0.05 to $1.2 \mathrm{mmol} / \mathrm{g}$ and from 0.03 to $0.58 \mathrm{mmol} / \mathrm{g}$, respectively. There are probably more protons in the solution with a lower $\mathrm{pH}$ level which forms $-\mathrm{NH}_{3}{ }^{+}$groups by protonating the amino groups of chitosan. This causes a rise in dye biosorption because of an increase in the electrostatic interaction between the protonated amino group $\left(-\mathrm{NH}_{3}{ }^{+}\right)$of chitosan and the anionic groups $\left(-\mathrm{SO}_{3}{ }^{-}\right.$and $\left.-\mathrm{OSO}_{3}{ }^{-}\right)$of the dye [8]. All the above biosorption interactions are also summarized in Fig. 6.

\subsection{Reusability}

Desorption is the reverse process of biosorption. It is quite significant because of its effect on the reusability

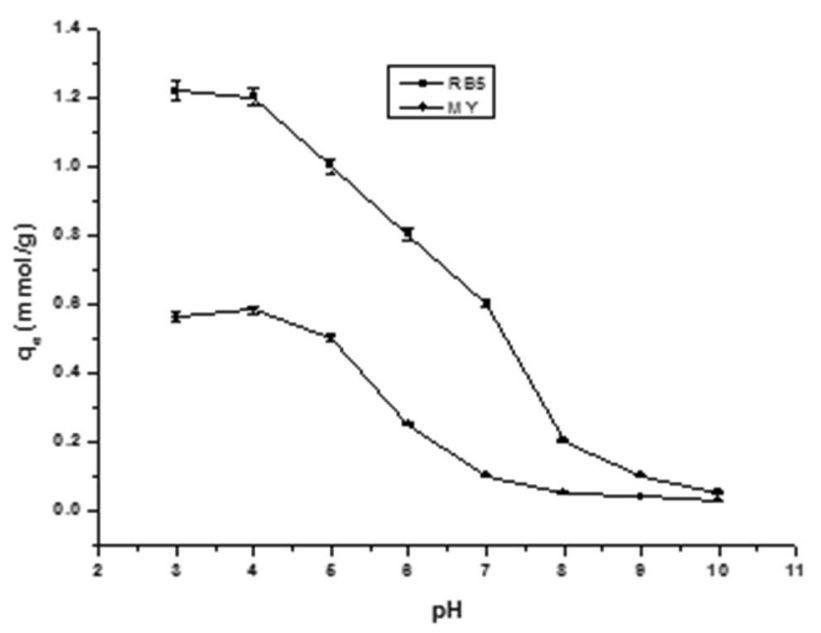

Fig. 5 Effect of $\mathrm{pH}$ on biosorption of the RB5 and MY onto the GMCNs
Table 3 Langmuir and Freundlich isotherm constants for anionic dyes $\left(\mathrm{pH} 3,30^{\circ} \mathrm{C}\right)$

\begin{tabular}{|c|c|c|c|c|c|c|c|}
\hline & \multicolumn{4}{|c|}{ Langmuir Constant } & \multicolumn{3}{|c|}{ Freundlich Constant } \\
\hline & $\begin{array}{l}Q_{m} \\
\left(\mathrm{mmolg}^{-1}\right)\end{array}$ & $\begin{array}{l}K_{L} \\
\left(\mathrm{dm}^{3} \mathrm{~g}^{-1}\right)\end{array}$ & $\begin{array}{l}b \\
\left(\mathrm{dm}^{3} \mathrm{mmol}^{-1}\right)\end{array}$ & $R^{2}$ & $\begin{array}{l}K_{F} \\
\left(\mathrm{dm}^{3}\right. \\
\left.\mathrm{g}^{-1}\right)\end{array}$ & $b_{F}$ & $R^{2}$ \\
\hline RB5 & 2.57 & 15.70 & 6.13 & 0.997 & 2.24 & 0.12 & 0.383 \\
\hline MY & 1.65 & 3.37 & 2.04 & 0.980 & 1.14 & 0.30 & 0.551 \\
\hline
\end{tabular}




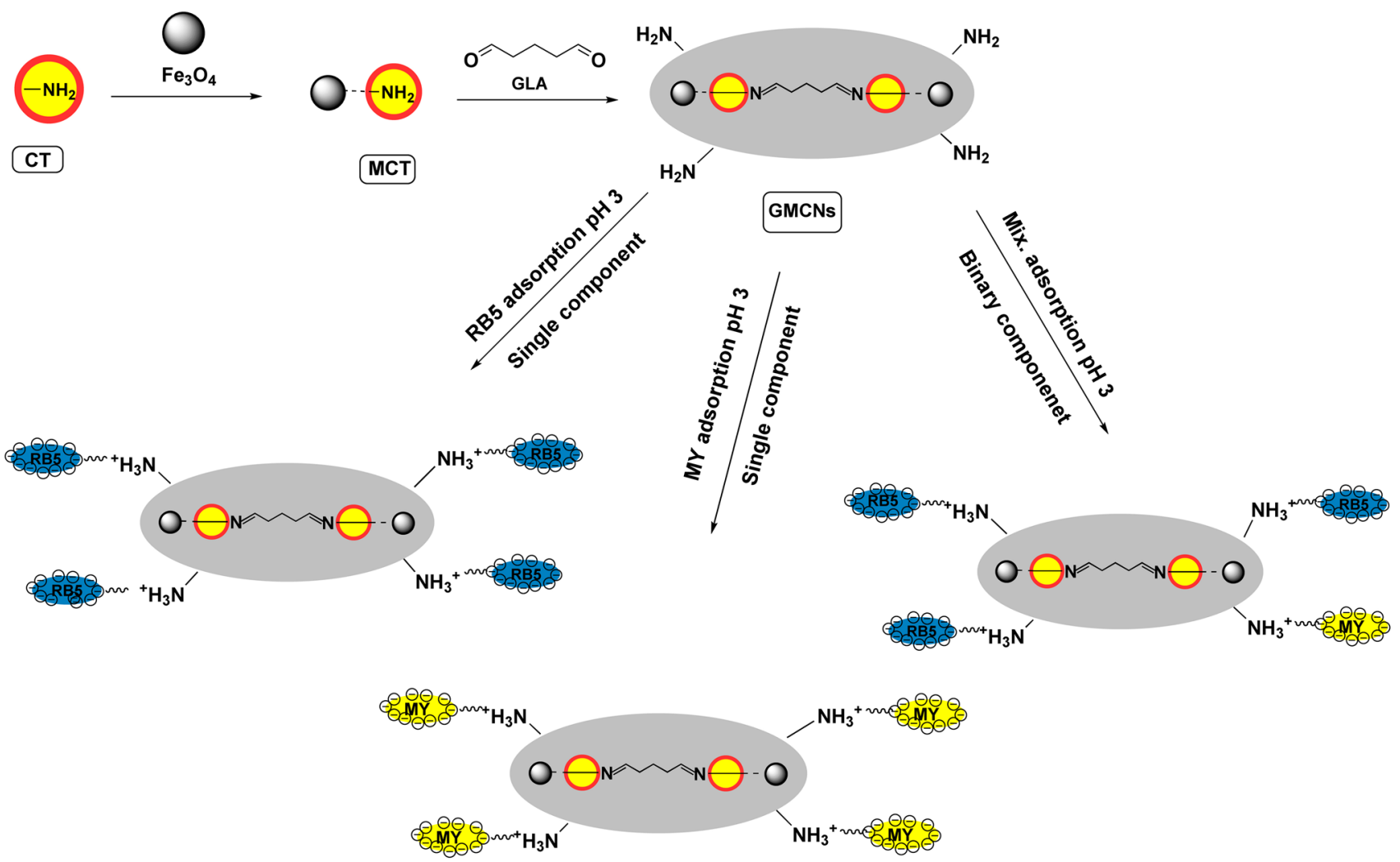

Fig. 6 Proposed biosorption mechanism of the RB5 and MY biosorption onto the GMCNs

of biosorbent. To find out the optimum $\mathrm{pH}$ desorption value, $\mathrm{pH}$-effect experiments were conducted (data not indicated) and it was ascertained that the optimum $\mathrm{pH}$ value was 10 . The basis of biosorption interactions was electrostatic, so during desorption process, electrostatic interaction should be eliminated. The dye on the surface of GMCNs is desorbed by breaking their electrostatic interaction bonds at $\mathrm{pH} 10$. With the intention of finding out the reusability of the GMCNs, biosorption-desorption process was repetitive ten times $-17 \mathrm{~h}$ for each process-during 25 days. The results are given in Fig. 7 . The loss in the removal ability for the RB5 dye during the biosorption and desorption processes was very little. In the first stage, the removal ability was $94 \%$, and in the 5 th stage, the removal percent was $90 \%$, so the loss was $4 \%$. Until the last stage (10th), the total loss in the removal ability for the RB5 dye was $10 \%$. On the other hand, the reusability of GMCNs in the MY dye was lower than the RB5 dye. The decrease in the reusability of GMCNs in the MY dye was 5\% for each cycle. The removal of percents in cycles was as follows: for the $1 \mathrm{st}$ cycle: $53 \%$; 5 th: $48 \%$; 10th: $47 \%$. This difference between the dye and the RB5 can arise from the gradual damage occurred on the surface of GMCNs.

\subsection{Competition biosorption}

The kinetics of the competition biosorption of the admixture solution A (preliminary concentration of the RB5 $0.67 \mathrm{mM}$ and the MY $0.67 \mathrm{mM}$ ) consists of the RB5, and MY dyes on the GMCNs were performed at a temperature of $30^{\circ} \mathrm{C}$ and at the level of $3.0 \mathrm{pH}$. The beginning biosorption rate of the MY dye onto the GMCNs in the admixture solution A was slower than that of the RB5 dye. This may be ascribed to the fact that the MY dye has less suitable sites for the biosorption on the GMCN nanoparticles than RB5 dye molecules. Figure 8 shows that the capacity of biosorption of the RB5 dye was found $0.46 \mathrm{mmol} / \mathrm{g}$, whereas that of the MY dye appeared to be only $0.24 \mathrm{mmol} / \mathrm{g}$. In order to study the competition biosorption in the admixture with a higher concentration of the MY dye, the admixture solutions $B$, the admixture with the initial concentration of the RB5 $0.67 \mathrm{mM}$ dye and the initial concentration of the MY dye $1.33 \mathrm{mM}$, was used at a temperature of $30^{\circ} \mathrm{C}$ and at $\mathrm{pH}$ of 3.0. The biosorption rates of the RB5 dye onto the GMCNs were significantly faster rather than that of the MY dye. In spite of a higher molar concentration in the MY dye, there was a weaker driving force in the biosorption process $[8,11]$. 
Fig. 7 Cycles of biosorptiondesorption for the reuse of GMCNs for the RB5 and MY biosorption

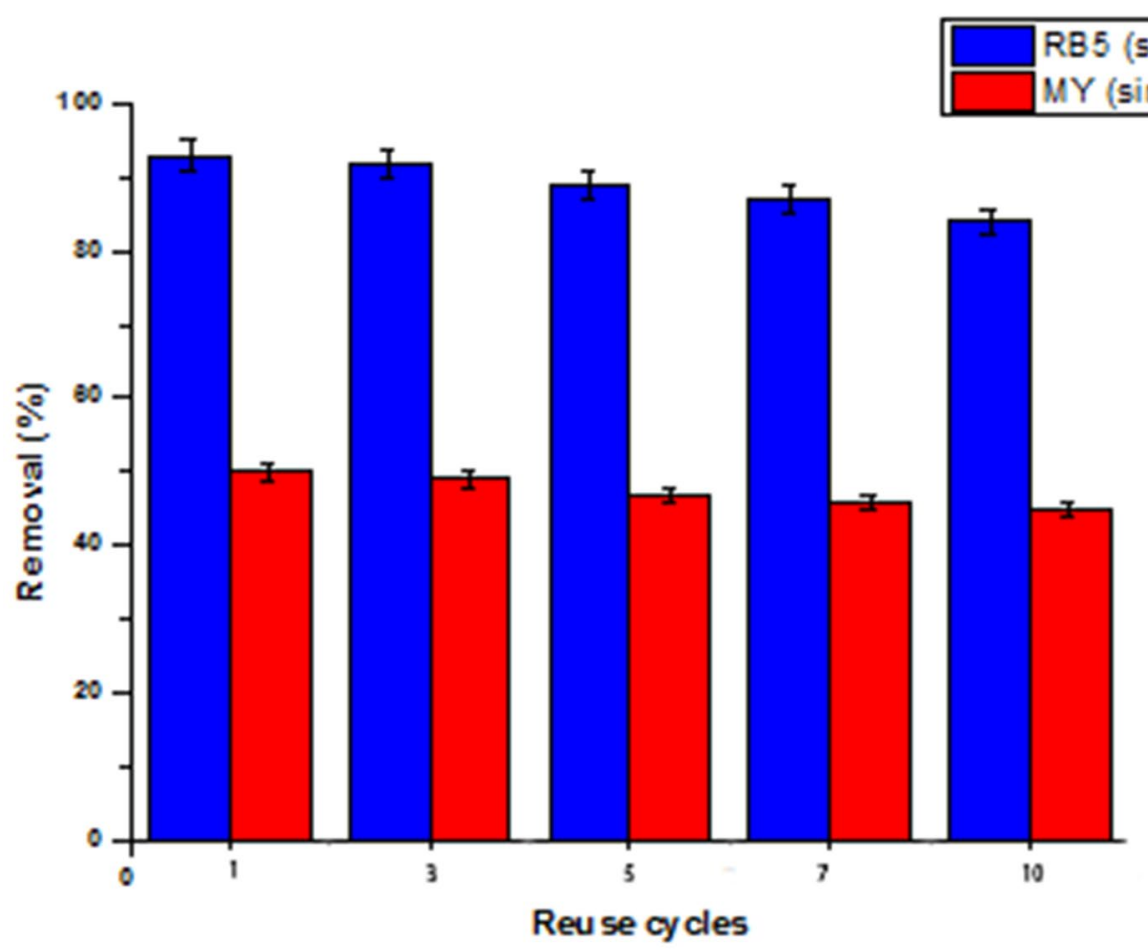

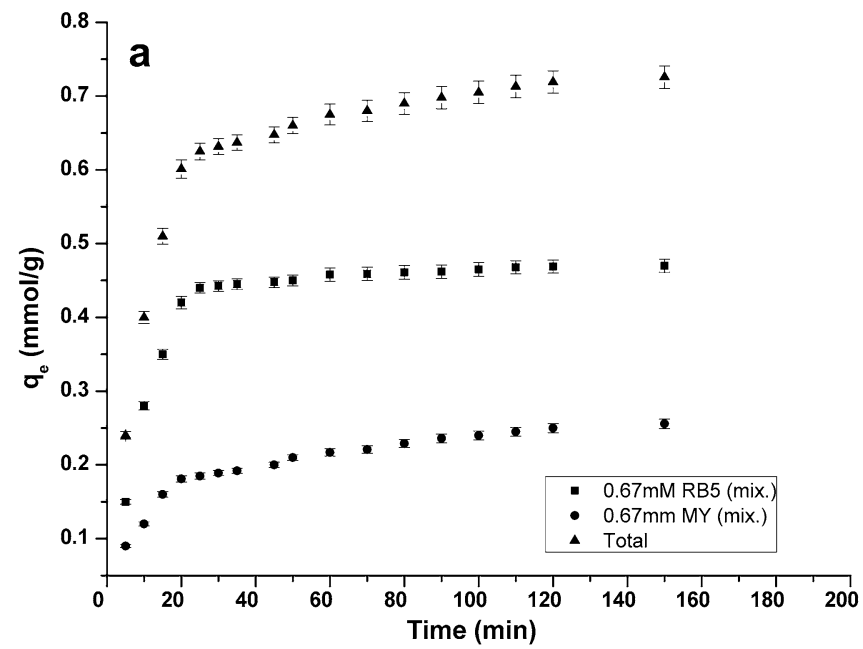

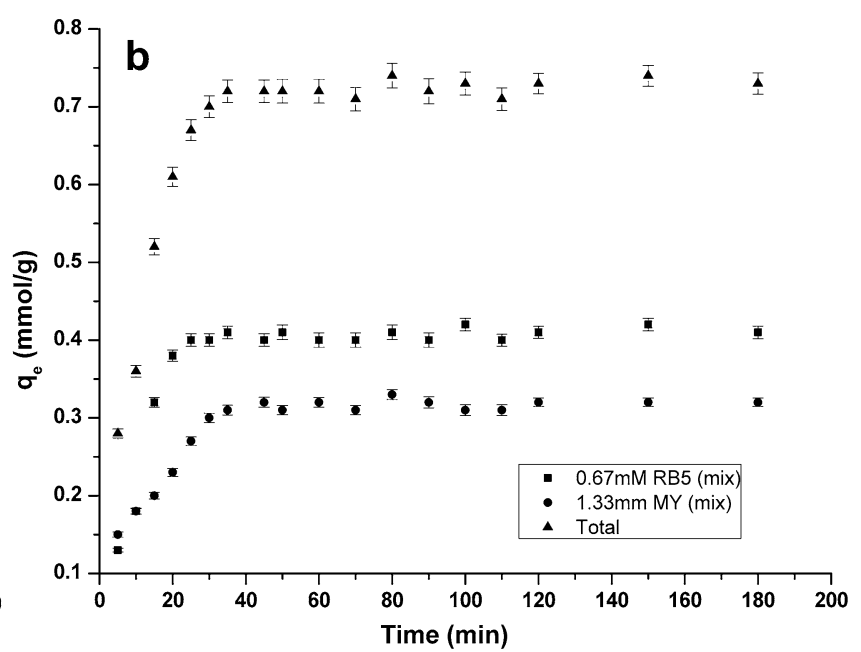

Fig. 8 Kinetics of the biosorption capacity of a the admixture solution A (preliminary concentration of the RB5 $0.67 \mathrm{mM}$ and MY $0.67 \mathrm{mM}$ ) and $\mathbf{b}$ the admixture solution $\mathrm{B}$ (preliminary concentration of the RB5 $0.67 \mathrm{mM}$ and $\mathrm{MY} 1.33 \mathrm{mM}$ ) onto the $\mathrm{GMCNs}$ at $\mathrm{pH} 3,30^{\circ} \mathrm{C}$

Although the MY concentration in the admixture solution $B$ is twice as high as the RB5, the biosorption rate of the RB5 is still considerably higher than that of the MY. When the biosorption equilibrium time of single dye is compared to the biosorption equilibrium time of coloring agents in the admixture, it is seen that the coloring agents in the admixture were equilibrated much more quickly. Table 4 shows the biosorption ratio of the MY and RB5 dyes on the GMCNs by using the second-order and first-order kinetic models for the admixture solutions A with B, respectively. In Table 4, there is a comparison of the linear correlation coefficients $\left(R^{2}\right)$ and it shows that the second-order kinetic model is better than the first-order model and fits well for mixture solutions $A$ and $B$ [8].

In order to study the competition biosorption of the RB5 and $M Y$ dyes in mixture solutions $A$ and $B$, the intraparticle 
Table 4 First-order and second-order rate constants and intraparticle diffusion parameters for different mixture solutions of the RB5 and MY dyes on the GMCNs at beginning $\mathrm{pH} 3.0$ and at $30^{\circ} \mathrm{C}$

\begin{tabular}{|c|c|c|c|c|c|c|c|c|c|}
\hline \multirow{2}{*}{\multicolumn{2}{|c|}{$\begin{array}{l}\text { Initial con- } \\
\text { centration } \\
(\mathrm{mM})\end{array}$}} & \multicolumn{3}{|c|}{ Second-order kinetic model } & \multicolumn{3}{|c|}{ First-order kinetic model } & \multicolumn{2}{|c|}{$\begin{array}{l}\text { Intraparticle Dif- } \\
\text { fusion Model }\end{array}$} \\
\hline & & $\begin{array}{l}k_{2} \\
(\mathrm{~g} / \mathrm{mmol} \mathrm{min})\end{array}$ & $\begin{array}{l}q_{e} \\
(\mathrm{mmol} / \mathrm{g})\end{array}$ & $R^{2}$ & $\begin{array}{l}k_{1} \\
\left(\min ^{-1}\right)\end{array}$ & $\begin{array}{l}q_{e} \\
(\mathrm{mmol} / \mathrm{g})\end{array}$ & $R^{2}$ & $k_{p, 2}$ & $k_{p, 3}$ \\
\hline MY & 0.665 & 0.269 & 0.275 & 0.998 & 0.024 & 0.164 & 0.964 & 0.0296 & 0.0089 \\
\hline RB5 & 0.665 & 0.200 & 0.490 & 0.998 & 0.025 & 0.116 & 0.829 & 0.1193 & 0.0094 \\
\hline MY & 1.33 & 0.556 & 0.333 & 0.997 & 0.046 & 0.184 & 0.777 & 0.046 & 0.0019 \\
\hline RB5 & 0.665 & 0.452 & 0.429 & 0.995 & 0.029 & 0.099 & 0.479 & 0.1182 & 0.0028 \\
\hline
\end{tabular}

diffusion model was used. The equation for intraparticle diffusion is described as Eq. (9):

$Q_{t}=k_{i} t^{0.5}+C$

where $Q_{t}, k_{i}$ and $C$ are biosorption capacities of dye at a given time $t$, intraparticle diffusion rate constant and a constant, respectively. $k_{i}(i=1-3)$ is the slope of the straight-line portions of the plot of $Q_{t}$ versus the square root of time $\left(t^{0.5}\right)$. As seen in Fig. 9, multilinearities were observed through $\mathrm{t}^{0.5}$ versus the plot of $\mathrm{Q}_{\mathrm{t}}$ for the competition biosorption of the MY and RB5 dyes on the GMCNs in the admixture solutions $A$ and $B$. Because the first stage (outer surface biosorption) is ended fast, it is less clear. In Fig. 9, the second portion which is the gradual biosorption stage and the third portion which is the final equilibrium stage are only shown. In the second portion, intraparticle diffusion is rate limiting, and in the third portion, because of the extremely low solute concentration in the solution, intraparticle diffusion starts to slow down $[9,11]$. According to Fig. 9, the slope of the line in each stage was indicated as the rate parameter $k_{p, i}(i=1-3)$. Table 4 shows that the sequence of biosorption rate is $k_{p, 2}>k_{p, 3}$ for each dye

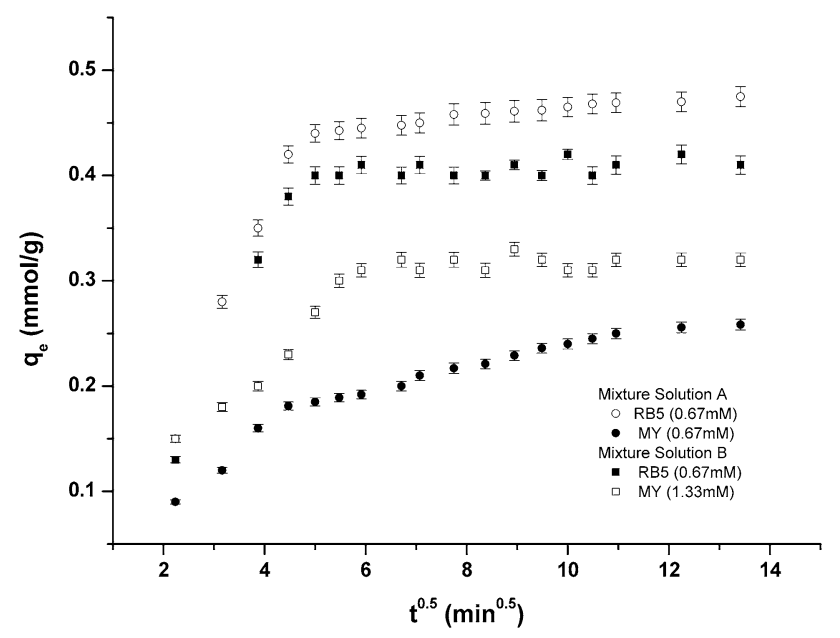

Fig. 9 Intraparticle diffusion model to describe the competitive biosorption for the admixture solutions $A$ and $B$ in mixtures [11]. In A and B mixture solutions, the $k_{p, 2}$ of RB5 is much greater than the $k_{p, 2}$ of MY. It is because the molecule of RB5 diffuses faster. Furthermore, in mixture solution $A$ and $B$, the values of $k_{p, 3}$ for the RB5 and the MY dye on the GMCN nanoparticles were close to each other. It indicates that the existence of two dyes in the mixture does not affect the diffusion rate of each other.

\section{Conclusion}

The aim of this study was to find out the equilibrium and the dynamics of the biosorption of two anionic dyes (MY and RB5) on the chemically cross-linked chitosan. The cross-linked chitosan had high biosorption capacities to remove the anionic dyes. The maximum monolayer biosorption capacities for MY dye and RB5 dye are $620 \mathrm{mg} \mathrm{g}^{-1}$ and $2549 \mathrm{mg} \mathrm{g}^{-1}$, respectively, at $\mathrm{pH} 3$ and at the temperature of $30^{\circ} \mathrm{C}$. The initial concentration of dye and $\mathrm{pH}$ value affects the biosorption capacities significantly. The increase in the initial concentration of dye and decrease in $\mathrm{pH}$ increase the amount of adsorbed dye. The strong electrostatic interaction between the $-\mathrm{NH} 3+$ of chitosan and dye anions can be used to explain the high biosorption capacity of anionic dyes onto chemically cross-linked chitosan. The equilibrium isotherm has good compatibility with the Langmuir equation. The secondorder kinetic model fits well with the dynamical biosorption behavior of a single dye for RB5 and MY dye. At the same time, the second-order kinetic model fits well for mixture solutions. By using alkaline solution, the adsorbed dyes on the GMCNs can be desorbed efficiently, and for dyes removal, the GMCNs can be recycled. We conclude that this technique not only provides a higher biosorption capacity but is also a convenient and economical method for efficient biosorption of dyes in aqueous solutions.

Acknowledgements This project is funded by the financial support from Dicle University Research Fund (DUBAP, 13-ZEF-28, ZGEF.16.008, ZGEF.17.008). 


\section{Compliance with ethical standards}

Conflicts of interest There are no conflicts to declare.

\section{References}

1. Abdul Nabi A, Hussain A (2012) Synthesis, identification and study of some new azo dyes as corrosion inhibitors for carbonsteel in acidic media. J Basrah Res (Sci) 38:125

2. Al-Rubaie L, Mhessn RJ (2012) Synthesis and characterization of azo dye para red and new derivatives. J Chem 9:465-470

3. Anastopoulos I, Hosseini-Bandegharaei A, Fu J, Mitropoulos AC, Kyzas GZ (2017) Use of nanoparticles for dye adsorption: review. J Dispersion Sci Technol 39:836-847. https://doi. org/10.1080/01932691.2017.1398661

4. Assémian AS, Kouassi KE, Drogui $P$, Adouby K, Boa D (2018) Removal of a persistent dye in aqueous solutions by electrocoagulation process: modeling and optimization through response surface methodology. Water Air Soil Pollut 229:184. https://doi.org/10.1007/s11270-018-3813-2

5. Chatterjee S, Chatterjee S, Chatterjee BP, Das AR, Guha AK (2005) Adsorption of a model anionic dye, eosin $Y$, from aqueous solution by chitosan hydrobeads. J Colloid Interface Sci 288:30-35

6. Chen AH, Huang YY (2010) Adsorption of Remazol Black 5 from aqueous solution by the templated crosslinked-chitosans. J Hazard Mater 177:668-675

7. Chen AH, Chen SM (2009) Biosorption of azo dyes from aqueous solution by glutaraldehyde-crosslinked chitosans. J Hazard Mater 172:1111-1121

8. Chen CY, Chang JC, Chen $\mathrm{AH}$ (2011) Competitive biosorption of azo dyes from aqueous solution on the templated crosslinkedchitosan nanoparticles. J Hazard Mater 185:430-441

9. Cheung W, Szeto Y, McKay G (2007) Intraparticle diffusion processes during acid dye adsorption onto chitosan. Biores Technol 98:2897-2904

10. Chiou MS, Ho PY, Li HY (2004) Adsorption of anionic dyes in acid solutions using chemically cross-linked chitosan beads. Dyes Pigm 60:69-84

11. Chiou MS, Chuang GS (2006) Competitive adsorption of dye metanil yellow and RB15 in acid solutions on chemically crosslinked chitosan beads. Chemosphere 62:731-740

12. Chiou MS, Li HY (2002) Equilibrium and kinetic modeling of adsorption of reactive dye on cross-linked chitosan beads. J Hazard Mater 93:233-248

13. Chiou MS, Li HY (2003) Adsorption behavior of reactive dye in aqueous solution on chemical cross-linked chitosan beads. Chemosphere 50:1095-1105

14. Crini G, Badot PM (2008) Application of chitosan, a natural aminopolysaccharide, for dye removal from aqueous solutions by adsorption processes using batch studies: a review of recent literature. Prog Polym Sci 33:399-447

15. Du WL, Xu ZR, Han XY, Xu YL, Miao ZG (2008) Preparation, characterization and adsorption properties of chitosan nanoparticles for eosin Y as a model anionic dye. J Hazard Mater 153:152-156

16. Elwakeel KZ (2009) Removal of Reactive Black 5 from aqueous solutions using magnetic chitosan resins. J Hazard Mater 167:383-392

17. Guibal E, Dambies L, Milot C, Roussy J (1999) Influence of polymer structural parameters and experimental conditions on metal anion sorption by chitosan. Polym Int 48:671-680

18. Hamzeh Y, Ashori A, Azadeh E, Abdulkhani A (2012) Removal of Acid Orange 7 and Remazol Black 5 reactive dyes from aqueous solutions using a novel biosorbent. Mater Sci Eng $C$ 32:1394-1400

19. Hu ZG, Zhang J, Chan WL, Szeto YS (2006) The sorption of acid dye onto chitosan nanoparticles. Polymer 47:5838-5842

20. Kamari A, Ngah WSW, Chong MY, Cheah ML (2009) Sorption of acid dyes onto GLA and $\mathrm{H} 2 \mathrm{SO} 4$ cross-linked chitosan beads. Desalination 249:1180-1189

21. Kyzas GZ, Matis KA (2015) Nanoadsorbents for pollutants removal: a review. J Mol Liq 203:159-168. https://doi. org/10.1016/j.molliq.2015.01.004

22. Pearce Cl, Lloyd JR, Guthrie JT (2003) The removal of colour from textile wastewater using whole bacterial cells: a review. Dyes Pigm 58:179-196

23. Peternel IT, Koprivanac N, Bozic AM, Kusic HM (2007) Comparative study of UV/TiO2, UV/ZnO and photo-Fenton processes for the organic reactive dye degradation in aqueous solution. $J$ Hazard Mater 148:477-484

24. Rosa S, Laranjeira MC, Riela HG, Favere VT (2008) Cross-linked quaternary chitosan as an adsorbent for the removal of the reactive dye from aqueous solutions. J Hazard Mater 155:253-260

25. Tural B (2010) Separation and preconcentration of boron with a glucamine modified novel magnetic sorbent. Clean Soil Air Water 38:321-327

26. Tural B, Tural S, Demir AS (2013) Carboligation reactions mediated by benzoylformate decarboxylase immobilized on a magnetic solid support. Chirality 25:415-421

27. Tural S, Tural B, Ece MS, Yetkin E, Ozkan N (2014) Kinetic approach for the purification of nucleotides with magnetic separation. J Sep Sci 37:3370-3376

28. Tural S, Tarhan T, Tural B (2016) Removal of hazardous azo dye Metanil Yellow from aqueous solution by cross-linked magnetic biosorbent; equilibrium and kinetic studies. Desalin Water Treatment 57:13347-13356

29. Tural B, Ertaş E, Enez B, Fincan SA, Tural S (2017) Preparation and characterization of a novel magnetic biosorbent functionalized with biomass of Bacillus subtilis: kinetic and isotherm studies of biosorption processes in the removal of methylene blue. $J$ Environ Chem Eng 5:4795-4802

30. Umpuch C, Sakaew S (2015) Adsorption characteristics of reactive black 5 onto chitosan-intercalated montmorillonite. Desalin Water Treatment 53:2962-2969

31. Vijayaraghavan K, Yun YS (2008) Biosorption of CI Reactive Black 5 from aqueous solution using acid-treated biomass of brown seaweed Laminaria sp. Dyes Pigm 76:726-732

32. Wang J, Yan Y, Tian L, Wang Q, Zhang Y, Cao W, Yang C (2018) Efficient electrochemical oxidation of charged cryogel adsorbed reactive dyes in non-aqueous media. Water Air Soil Pollut 229:180. https://doi.org/10.1007/s11270-018-3833-y

33. Wu FC, Tseng RL, Juang RS (2001) Enhanced abilities of highly swollen chitosan beads for color removal and tyrosinase immobilization. J Hazard Mater 81:167-177

34. Wu FC, Tseng RL, Juang RS (2000) Comparative adsorption of metal and dye on flake- and bead-types of chitosans prepared from fishery wastes. J Hazard Mater 73:63-75

35. Wu W, He Q, Jiang C (2008) Magnetic Iron Oxide Nanoparticles: synthesis and Surface Functionalization Strategies. Nanoscale Res Lett 3:397-415

36. Yoshida H, Fukuda S, Okamoto A, Kataoka T (1991) Recovery of direct dye and acid dye by adsorption on chitosan fiber-equilibria. Water Sci Technol 23:1667-1676

37. Yuen CWM, Ku SKA, Choi PSR, Kan CW, Tsang SY (2005) Determining functional groups of commercially available ink-jet printing reactive dyes using infrared spectroscopy. Res J Text Appar 9:26-38 
38. Zhu H, Zhang M, Liu Y, Zhang L, Han R (2012) Study of congo red adsorption onto chitosan coated magnetic iron oxide in batch mode. Desalin Water Treatment 37:46-54
39. Zollinger $\mathrm{H}$ (2003) Color chemistry: syntheses, properties, and applications of organic dyes and pigments. Wiley, New York 